\title{
Telemedicine
}

\section{A guide to online resources}

W

ith rising healthcare costs and new insurance standards, healthcare has been out of the reach for many for far too long. Now that telemedicine is making a bigger splash in the pool of healthcare options, healthcare is finally becoming accessible for the masses.

According to the American Telemedicine Association, telemedicine is the "use of medical information exchanged from one site to another via electronic communications to improve a patient's clinical health status. Telemedicine includes a growing variety of applications and services using two-way video, email, smart phones, wireless tools and other forms of telecommunications technology." It is important to acknowledge that telemedicine should be viewed as a supplement to traditional medical delivery and not as an entirely separate medical practice.

Another term that is often used to describe similar health care delivery is telehealth. Described as a "collection of means or methods for enhancing health care, public health and health education delivery and support using telecommunication technologies."2Telehealth reaches more related fields of healthcare, such as dentistry, chronic disease monitoring and management, physical and occupational therapy, and counseling.

This technology helps provide a way for hospitals to share specialized treatment with patients outside of their immediate geographic radius. Telemedicine achieves the goal of providing patients with quicker, more specialized care in a safe digital environment. Data from various organizations suggests that that telemedicine patients are more likely to check in with their doctors and follow up with any new prescriptions or post-treatment testing. Another benefit of telemedicine is that altering follow-up visits for less sick patients could allow doctors to spend more time with patients who have more serious medical issues.

With limited doctors and a shortage of healthcare workers in many rural regions of the country, those in these areas are left to suffer. Thanks to Senate Bill 144, insurers in Oregon communities will not be required to pay the same cost for a remote visit as they do for an in-person visit. Cost-effective care delivery models such as the ones that will be described in the telehealth/telemedicine providers section are crucial to their well-being. With the rapid growth of this technology, the guide below is not comprehensive, but strives to feature a snapshot of interesting and informative telemedicine/telehealth resources.

\section{History/infographics}

- CDW Health. Created in 2013, this infographic alerted us that patient use of telehealth would sky rocket within three

Angela M. Gooden is director of Pre-College Academic Readiness Programs at The University of Texas-Austin, email: agooden@austin.utexas.edu

๑) 2016 Angela M. Gooden 
years. Advantages to telehealth and future trends are included. Access: http:// mhealthwatch.com/infographic-top-trends -in-telemedicine-21812/.

- Eagle Hospital Physicians. The seesaw of increased ICU patients and the projected decrease of qualified ICU intensivists fuels the discussion for the impetus to use telemedicine in the ICU. Current telemedicine use and cost savings are detailed. Access: http://blog.eaglehospitalphysicians.com/2015/08/infographic-why-use -telemedicine-in-icu.html.

- InHouse Physicians. Healthcare trends, including patient prescription delivery preference and health outcomes, are described in this 2015 infographic. Access: http://www.inhousephysicians.com/healthcare-trends-in-2015 -telemedicine-infographics-share/.

- Making Healthcare Universally Acceptable. This article from IEEE Pulse magazine, features a brief history of telemedicine through pictures. Telehealth technologies are also detailed in this timeline. Access: http://pulse.embs.org/november-2014 /making-health-care-universally-accessible/.

- MCOL (Managed Care On-Line). MCOL is a leading publisher of healthcare business information. Better patient care, improved access to health care, more productive workforce, and reduced health care costs are included in the four factors fueling the demand for telehealth. Access: http:// www.mcolblog.com/kcblog/2015/5/7/four -factors-fueling-demand-for-telehealth.html.

\section{Government/policy}

- Medicaid coverage. With its mission to keep America healthy, Medicaid uses this venue to describe telemedicine and share information on reimbursement for telemedicine terms and provider guidelines. The site briefly discusses provider and facility guidelines. Additionally, it emphasizes the use of telemedicine as a prudent way to reduce medical costs. Access: http://www.medicaid. gov/Medicaid-CHIP-Program-Information/ByTopics/Delivery-Systems/Telemedicine.html.
- Medicare coverage. The Medicare site outlines telehealth options that are covered. Costs and patient eligibility are also highlighted here. Now that Medicare is covering non in-person visits, this should prove to be a boon for groups that have limited funds but may have growing healthcare concerns. Access: https://www.medicare.gov/coverage /telehealth.html.

- State Laws and Reimbursement Policies with the Center for Connected Health Policy. A public interest group-The Center for Connected Health Policy-covers current and pending telehealth policy for all 50 states. Resources include fact sheets, publications, reports, and policy briefs. Current telehealth news and updates are also featured. Access: http://cchpca.org/statelaws-and-reimbursement-policies.

- The Office for the Advancement of Telehealth (OAT). Housed under the U.S. Department of Health and Human Services, OAT promotes the use of telehealth technologies for health information services and health care delivery. The Rural Child Poverty Network Grant Program and the Rural Veterans Health Access Growth Program are two examples of OAT funds allotted to benefit rural communities. Access: http://www.hrsa. gov/ruralhealth/telehealth/index.html.

\section{Academic}

- Arizona Telemedicine Program. This university-based multidisciplinary program provides telemedicine services, informative training, and telemedicine technology assessment capabilities throughout Arizona. The telemedicine training program and deadlines are outlined. Distance education options include video streaming, webinars, and workshops. Network membership information is accessible. Access: http://www. telemedicine.arizona.edu/.

\section{- Medical University of South Caro-} lina. This site describes the work of the Center of Telehealth, which is designed to meet the needs of the South Carolina community. The telehealth programs here offer lifesaving treatment and specialty consulta- 
tion for patients all over the state. Information about school-based telehealth programs, education collaborative, and maternal fetal telemedicine programs are shared here, as well. Access: http://www.muschealth.org /telehealth/about/what-is/.

\section{- University of California (UC) Davis}

Health System. The telehealth education program is featured. As one of the earliest pediatric telemedicine programs, UC Davis specialists conduct an average of more than 2,800 telemedicine consultations each year. Adult specialty care includes cardiology, genomic medicine, otolaryngology, and general thoracic surgery. Access: http://www. ucdmc.ucdavis.edu/cht/clinic/index.html.

- University of Nevada School of Medicine. In collaboration with the Nevada State Office of Rural Health, the University of Nevada School of Medicine strives to

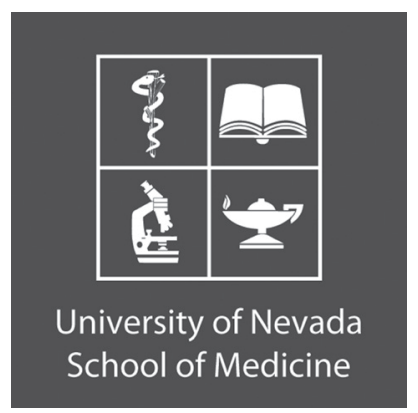

remove barriers to quality healthcare in Nevada's rural communities. Statistics and ou t comes measures are also listed on this site. Access: http://medicine.nevada.edu/statewide /rural-health/telehealth.

- University of Pittsburgh Medical Center (UPMC). Services this academic health center provides include telestroke, teletrauma, teleICU, teleradiology, and telerheumatology. Using the tabs on the left, patients and families can easily determine where the teleconsult centers are located throughout the state. UPMC strives to connect rural and small hospitals with its specialists. Thanks to relationships with outlying facilities, UPMC is able to share its expertise and deliver emergency care to patients. Curious about UPMC's charity care or community benefits? Check out the UPMC Facts and Stats section. Access: http://www. upmc.com/HEALTHCARE-PROFESSIONALS /PHYSICIANS/TELEMEDICINE/.
- University of Vermont Medical Center. This site focuses on providing care for the rural Vermont areas, including teledialysis, palliative care, pediatric emergency care, and surgical follow up. The University of Vermont Medical Center also uses telemedicine to provide course lectures and educational offerings to healthcare professionals. Clinical and nonclinical telemedicine options are presented. Need help with your videoconferencing? Technical support information is also available. Access: https://www.uvmhealth.org/medcenter/Pages/Departments -and-Programs/Telemedicine.aspx.

- University of Virginia Health System. Patients can feel at ease when reviewing the steps on what to expect as the process is outlined via the how-to participate section. Clinical services include diabetes education, liver treatment, plastic surgery, and pulmonary. Distance learning opportunities are offered for health care professionals as well as for patients. Access: http://uvahealth.com/services/telemedicine -telehealth-services.

\section{State programs}

- Alabama Public Health. Mostly geared toward Alabama Department of Public Health employees and collaborating partners, this site includes a visual listing of Alabama network sites, network video, and links to other southeast telemedicine-focused states. The additional resources link will lead you to legislation policies, best practices, and fact sheets. Access: http://www.adph.org /ALPHTN/Default.asp?id=6924.

- Georgia Partnership for Telehealth (GPT). With a slant toward rural communities, GPT touts themselves as an applier of telemedicine. Conference information for the Georgia Partnership for Telehealth can be found on the site. Recent GPT news is delivered via their monthly newsletters. Access: http://gatelehealth.org/georgia-partnership -for-telehealth/.

\section{Scholarly journals}

- International Journal of Telemedicine and Applications. This open access 
journal published by Hindawi Publishing Corporation covers telemedicine techniques, applications, and continued growth in medical care at a distance. Tutorial papers with a slant toward multidisciplinary views of telemedicine are welcomed. Access: http:// www.hindawi.com/journals/ijta/.

- Journal of Telemedicine and Telec-

are. This peer-reviewed journal covers the gamut of clinical telemedicine practices, health policy, and regulation, in addition to issues related to quality, cost, and accessibility of care. Articles routinely cover unique areas around the world providing an informative view of how other countries are using new health care technologies. Access: http://jtt.sagepub.com/.

- Smart Homecare Technology and TeleHealth. This open access journal covers technology employed to improve the healthcare of assisted living and at-home patients. It also focuses on healthcare provider communication and education tools. The journal subscribes to the principles of the Committee on Publication Ethics. Access: https://www. dovepress.com/smart-homecare-technology -and-telehealth-journal.

- Telemedicine and e-Health. Clinical telemedicine practice, education, medical connectivity, health policy and regulation, and biomedical health services research are all covered here. Formerly known as Telemedicine Journal, it is the official journal of the American Telemedicine Association. Access: http://www.liebertpub.com/overview /telemedicine-and-e-health/54/.

\section{Telehealth/telemedicine providers}

- Inova Telemedicine Program. Based in the Northern Virginia area, this program serves more than 25 locations. Inova's enVision eICU has the distinction of being one of the first teleICU programs in the country.
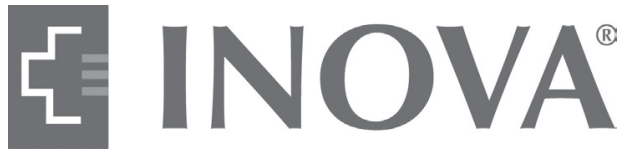

From this site, patients are able to learn more about the telestroke, telepsychiatry, telepedi- atrics, and teledermatology programs. Access: http://www.inova.org/healthcare-services /inova-telemedicine-program.

- MDLIVE. Since 2009, MDLIVE has served as a platform to connect U.S. patients with doctors for nonemergency care. Common conditions include sinus infection, cold/flu, headache, bronchitis, and asthma. MDLIVE's 24/7/365 availability makes it attractive for remote and not-so-remote users. Licensed and screened therapists (along with their pay rates) are easily browsable on the MDLIVE site via the Breakthrough interface. Access: https://www.mdlive.com/.

- Teladoc. The first and largest telehealth provider. With more than 11 million members, Teladoc provides its members with $24 / 7$ access to affordable and high-quality health care for nonemergency conditions. As a leader in the field, Teladoc strives to have its doctors contact patients within ten minutes. How's that for no waiting room lingering? Access: http://www.teladoc.com/.

\section{Organizations}

- American Telemedicine Association (ATA). ATA is a nonprofit organization established in 1993 and based in Washington, D.C. As the premier telemedicine association, ATA strives to improve the quality and equity of healthcare throughout the world by incorporating telemedicine into updated healthcare systems. Meetings, education resources, and case studies are easily available. The latest in public policy and industry news is discussed via monthly videocasts. The more than 9,000 ATA members include clinicians, doctors and nurses, healthcare administrators, and health IT engineers. The organization recently launched its resource center and product directory to give members access to the best products in telemedicine and healthcare. Access: http:// www.americantelemed.org/home.

- Center for TeleHealth and E-Health Law (CTeL). Created in 1995, this center is known as one of the distinguished associations in the telehealth field. CTeL strives to overcome legal and regulatory barriers that 
impede the delivery of telehealth services. Publications dealing with emerging legal and regulatory and issues can be found here. Access: http://ctel.org/.

\section{- Telehealth Alliance of Oregon}

(TAO). TAO is a nonprofit organization open to healthcare insurance providers, telehealth service providers, individuals, and students. The public can now access an inventory of Oregon telehealth services searchable via its recently opened portal. Access: http://www. ortelehealth.org/.

- Telehealth Resource Centers (TRC). Funded by the U.S. Department of Health and Human Services' Health Resources and Services Administration Office for the Advancement of Telehealth, this site is a consortium of telehealth centers. Training, legal, regulatory, and marketing modules are also covered. TRC provides the nuts and bolts of delivering medical care at a distance to organizations or individuals. Past webinars reach back to 2011. Access: http://www. telehealthresourcecenter.org/.

\section{Blogs}

- Federal Telemedicine News. This site has a collection of news briefs describing telemedicine and telehealth issues from a legislative and federal government perspective. The editor, Carolyn Bloch, has archives reaching back to 2008. Access: http://federaltelemedicine.com/?page_id=8.

- The Health Care Blog. More than 40 bloggers share input on this site created to cover healthcare industry topics and the business of healthcare. Readership includes medical students, doctors and nurses, state and federal level policymakers, and executives at healthcare networks. Book releases can be found here, as well. Access: http://thehealthcareblog.com/blog/tag/telemedicine/.

- Health Care Informatics. This blog, listed on the Healthcare Informatics page, is kept up-to-date by Heather Landi and others. IT-focused, legislative/policy, and academic research articles are often highlighted. $A c$ cess: http://www.healthcare-informatics. $\mathrm{com} /$ category/clinical/telemedicine.
- Learn Telehealth. University of Arkansas for Medical Sciences healthcare professionals Sarah Rhodes and Delbert McCutchen share their telehealth podcasts via SoundCloud. Forums and conferences are featured here, as well. The headers for each podcast start with fun Southern phrases like "Hey Y'all" or "Grab a glass of sweet tea." Access: http://learntelehealth.org/blog/.

\section{Notes}

1. See the American Telemedicine Associations site at www.americantelemed.org /about-telemedicine/what-is-telemedicine\#. VZ7UDbXnmRI.

2. See the Center for Connected Health Policy at http://cchpca.org/what-is -telehealth. $\boldsymbol{n}$

\section{C\&RL News seeks cover art}

CERL News is looking for images from library collections to feature on upcoming covers.

If you have items in your collections that you think would make attractive $C E R L$ News covers, we would love to see them.

To submit images (or image collections), send URLs for web-based images or images directly as attachments to David Free at dfree@ala.org. Please include a brief description of the item and your collection.

Images selected to appear as $C \varepsilon R L$ News covers will require a high-resolution electronic image (300 dpi or higher) to be submitted prior to the publication date.

Images must be vertically oriented or it must be possible to crop the image to show a detail in vertical format. Both color and black-and-white images are accepted.

Works selected must be in the public domain, from institutions that own reproduction rights for the works, or express rights must be obtained from the copyright holder.

Complete guidelines for the submission of cover illustrations are available online at crln.acrl.org/site/misc/author.xhtml. 